\title{
Mechanical Physicial Properties of Chlorella-PVA based Bioplastic with Ultrasonic Homogenizer
}

\author{
H. A. Sabathini ${ }^{1}$, L. Windiani ${ }^{1}$, Dianursanti ${ }^{1}$, M. Gozan*, \\ ${ }^{1}$ Department of Chemical Engineering, Faculty of Engineering, University of Indonesia, Depok 16424, Indonesia
}

\begin{abstract}
Public demand for environmentally friendly packaging material especially in food industry is increasing. One of the many solutions invented for this problem is the development of biodegradable plastic. Biopolymer can be mixed with synthetic polymer to produce biodegradable films with properties suitable for varying applications. This study examines the mechanical physical properties of Chlorellapolyvinyl alcohol (PVA) based bioplastic by pre-treating the Chlorella powder with ultrasonic homogenizer. Variation of Chlorella concentration and temperature was done during the ultrasonication. Before being used as bioplastic base, pre-treated Chlorella with different concentrations were equated. Bioplastic films were then prepared with the pre-treated Chlorella powder and PVA using solvent casting method. Mechanical physical properties of the pre-treated Chlorella films then compared with non pretreated Chlorella film as control. Mechanical test shows the increasing of bioplastic tensile strength up to $15,3 \mathrm{kgf} / \mathrm{cm}^{2}$ and elongation percentage up to $99,63 \%$. Field emission scanning electron microscopy test shows the increasing of bioplastic homogenity and smoother surface with less pores. Fourier transform infrared analysis shows that there are crosslinkages between Chlorella and PVA. Thermal analysis by thermogravimetric analysis shows ultrasonication creates a more compact linkages. The performance of the film could suggest its potential as an eco-sustainable food packaging plastic material.
\end{abstract}

\section{Introduction}

Food packaging with sufficient mechanical strength and thermal stability is substantial in food products for food quality protection and safety. Majority of the food packaging nowadays are petroleum based plastic. Unfortunately, petroleum based plastic has chemical building blocks that might harm people and the environment, and its production and disposal contribute to an array of environmental problems [1]. Several precautions were developed such as the development of biodegradable plastic (bioplastic). Bioplastic is made from natural polymer materials (biopolymer) and is designed to accelerate the natural degradation of plastic by microorganisms. Generally, biopolymers are used to blend with synthetic polymers to improve bioplastic characteristics and extend its applications. It is desired to use other biomass as a source of bioplastic production that improves bioplastic characteristics and to avoid food source competition.

On the other hand, microalgae have been atracted as the most promisingly renewable resource for bioplastic production because of their faster growth rate, higher photosynthetic efficiency and biopolymer source. Microalgae perform oxygenic photosynthesis and are capable of taking up a large amount of $\mathrm{CO}_{2}$ [2]. The cultivation of microalgae can be enchanced by alteration of illumination during growth [3]. However, microalgae has relatively thick cell wall and large particles [4].

Ultrasonic technologies have been used as pre-treatment methods in various industrial fields for decades [5]. It is used to reduce small particles in a liquid so that they become uniformly small and evenly distributed.

In this work, microalgae pre-treatment and its conversion to bioplastic with addition of polyvinyl alcohol (PVA) as synthetic polymer were attempted. The effect of ultrasonication treatment on bioplastic characteristics such as elongation, tensile strength, thermal properties, Field emission scanning electron microscopy, and Fourier transform infrared (FTIR) was clarified.

\section{Materials and Methods}

\subsection{Materials}

Chlorella; polyvinyl alcohol; glycerol, analytical pure; citric acid; distilled water, (laboratory homemade). CMAG HS 7 IKA Hotplate Stirrer; BSA2245-CW sartorius analytical balance; glass plate, (laboratory homemade); SK7210HP Kudos ultrasonic; Universal Testing Machine - Shimadzu; Scanning Electron Microscope - JEOL JSM-6510 LA; Thermal Gravimetry Analyzer - Mettler Toledo; Fourier Transform Infrared spectroscopy.

\subsection{Methods}

\subsubsection{Biomass Pre-treatment}

Chlorella: distilled water $(\mathrm{C} / \mathrm{W})$ solutions were treated with ultrasonic homogenizer. Dry 2,8 g of Chlorella powder was added into distilled water and then mixed with magnetic stirrer followed by ultrasonic treatment using a homogenizer (Merk) $53 \mathrm{kHz}$ for 40 
minutes. The treatment was done by the extraction method of starch from microalgae as described by Asada et al [5]. The test design of composisiton of this pretreatment is presented in Table 1 .

Table 1. Test design of composition.

\begin{tabular}{|c|c|c|c|c|}
\hline Solution & Chlorella $(\mathbf{g})$ & Distilled water $(\mathbf{m L})$ & Temperature $\left({ }^{\circ} \mathbf{C}\right)$ & Time (min) \\
\hline $\mathrm{C} / \mathrm{W}^{1: 3}$ & 2,8 & 8,4 & 25 & 40 \\
\hline $\mathrm{C} / \mathrm{W}^{1: 5}$ & 2,8 & 14 & 25 & 40 \\
\hline $\mathrm{C} / \mathrm{W}^{1: 10}$ & 2,8 & 28 & 25 & 40 \\
\hline $\mathrm{C} / \mathrm{W}^{1: 3}$ & 2,8 & 8,4 & 50 & 40 \\
\hline $\mathrm{C} / \mathrm{W}^{1: 5}$ & 2,8 & 14 & 50 & 40 \\
\hline $\mathrm{C} / \mathrm{W}^{1: 10}$ & 2,8 & 28 & 50 & 40 \\
\hline
\end{tabular}

composition. First, 2,8 g of PVA was dissolved in $10 \mathrm{~mL}$

The solutions were taken and added with distilled water until Chlorella: distilled water of each solutions equals 1:10 for usage in the next method.

\subsubsection{Preparation of films}

Chlorella/Polyvinyl alcohol (PVA) blend films were prepared using the solvent casting method as described by Wang et al. [1] with modification of solution temperature, and all the bioplastic have the same of distilled water at $80{ }^{\circ} \mathrm{C}$ while Chlorella solution was added with $2,11 \mathrm{~g}$ of glycerol and heated at $90{ }^{\circ} \mathrm{C}$. Thereafter, $1 \mathrm{~g}$ of citric acid was added to the PVA solution at $80^{\circ} \mathrm{C}$ alongside with the addition of Chlorella and glycerol solution and were stirred for 30 minutes. All the solutions were cast onto glass plate $(15 \mathrm{~cm} \mathrm{x} 15$ $\mathrm{cm})$ and were dried for $24 \mathrm{~h}$ at room temperature and peeled off from the plate to obtain a dried film.

Table 2. Blend films composition.

\begin{tabular}{|c|c|c|c|c|}
\hline Chlorella Solution & Polyvinyl Alcohol (g) & Distilled Water $(\mathbf{m L})$ & Glycerol (g) & Citric Acid (g) \\
\hline $\mathrm{C} / \mathrm{W}^{1: 3}$ & 2,8 & 10 & 2,11 & 1 \\
\hline $\mathrm{C} / \mathrm{W}^{1: 5}$ & 2,8 & 10 & 2,11 & 1 \\
\hline $\mathrm{C} / \mathrm{W}^{1: 10}$ & 2,8 & 10 & 2,11 & 1 \\
\hline $\mathrm{C} / \mathrm{W}^{1: 3}$ & 2,8 & 10 & 2,11 & 1 \\
\hline $\mathrm{C} / \mathrm{W}^{1: 5}$ & 2,8 & 10 & 2,11 & 1 \\
\hline $\mathrm{C} / \mathrm{W}^{1: 10}$ & 2,8 & 10 & 2,11 & 1 \\
\hline
\end{tabular}

\subsubsection{Mechanical Properties}

The mechanical properties of the films were analyzed by measuring the tensile strength (TS) and elongation at break (E) according to the standard ASTM method D882-12 using an Shimadzu Universal Testing Machine.

\subsubsection{Thermal Properties}

The thermal stability of film samples was evaluated according to the standard ASTM method D1131-14 using a Mettler Toledo thermogravimetric analyzer.

\subsubsection{Surface Morphology and FTIR Analysis}

The surfaces of the films were fixed with conductive adhesive and were sprayed with platina. The composite films were observed using a field JEOL JSM-6510 LA Scanning Electron Microscope.

By using Spectrum 100 Fourier transform infrared spectroscopy (FT-IR), spectroscopy analysis was performed.

\section{Results and Discussion}

\subsection{Mechanical Properties}

Mechanical properties such as tensile strength and elongation of the Chlorella/PVA blend films are shown in Table 3. Tensile test result shows that $\mathrm{C} / \mathrm{W}^{1: 5: 25}$ doubles the tensile strength and elongation percentage of Chlorella based bioplastic film (control). Optimum composition of solvent in a sonication process depends on the cell particle size and thickness [6]. Asada et al. (2012) [5] research shows that microalgae concentration of $1 \mathrm{~g} / \mathrm{mL}$ in sonication treatment resulting in starch extraction ratio of $93,8 \%$. Optimum condition of sonication resulting in higher amount of cell disruption and more dispersed particles which allows water molecule to intervene the polymer chain thus resulting in more flexible bioplastic film. Temperature also takes a big role in this reaction [5]. The higher the temperature, the weaker polymer bond will be, thus the easier water molecule to intervene the polymer chain. The tensile 
strength properties peak is at the Chlorella:water ratio of 1:5 because the amount of polymer-polymer bonds is equivalent to the amount of polymer-plasticizer bonds, while ratio of 1:3 has a higher amount of polymerpolymer bonds than the polymer-plasticizer bonds, and the ratio of $1: 10$ has higher amount of polymerplasticizer bonds than the amount of polymer-polymer bonds. As a result, the optimum condition of Chlorella sonication is Chlorella:water ratio of 1:5 with the temperature of $25^{\circ} \mathrm{C}$.
The result of comparing Chlorella-PVA based bioplastic film with ultrasonic pre-treatment with Chlorella-PVA based bioplastic film without ultrasonic pre-treatment shows that ultrasonication increases the tensile strength of the film up to $1,8 \mathrm{x}$ and increases the elongation percentafe up to $2,5 \mathrm{x}$. This shows that ultrasonication improves the mechanical characteristic of ChlorellaPVA based bioplastic film.

Table 3. Tensile properties of Chlorella/polyvinyl alcohol blend films.

\begin{tabular}{|c|c|c|c|c|}
\hline \multirow{2}{*}{ Sample } & \multicolumn{2}{|c|}{ Chlorella Ultrasonication Condition } & \multirow{2}{*}{ Tensile Strength $\left(\mathbf{k g f} / \mathbf{c m}^{2}\right)$} & \multirow{2}{*}{ Elongation (\%) } \\
\cline { 2 - 3 } & Chlorella:water ratio & Temperature $\left.\mathbf{~}^{\mathbf{0}} \mathbf{C}\right)$ & & \\
\hline $\mathrm{C} / \mathrm{W}^{1: 3: 25}$ & $1: 3$ & 25 & $32,9 \pm 3,5$ & $92,20 \pm 13,77$ \\
\hline $\mathrm{C} / \mathrm{W}^{1: 5: 25}$ & $1: 5$ & 25 & $35,1 \pm 4,3$ & $127,50 \pm 18,99$ \\
\hline $\mathrm{C} / \mathrm{W}^{1: 10: 25}$ & $1: 10$ & 25 & $20,8 \pm 1,5$ & $159,60 \pm 35,75$ \\
\hline $\mathrm{C} / \mathrm{W}^{1: 3: 25}$ & $1: 3$ & 50 & $23,8 \pm 1,1$ & $132,90 \pm 32,27$ \\
\hline $\mathrm{C} / \mathrm{W}^{1: 5: 25}$ & $1: 5$ & 50 & $28,8 \pm 1,5$ & $149,90 \pm 54,19$ \\
\hline $\mathrm{C} / \mathrm{W}^{1: 10: 25}$ & $1: 10$ & 50 & $15,2 \pm 2,7$ & $210,90 \pm 73,41$ \\
\hline Chlorella Control & No sonication & No sonication & $19,8 \pm 3,0$ & $27,87 \pm 3,16$ \\
\hline
\end{tabular}

\subsection{Thermal Properties}

TGA thermograms of Chlorella based bioplastic film with ultrasonic pre-treatment shows that the initial thermal decomposition at $80-140{ }^{\circ} \mathrm{C}$ was due to evaporation of water accounting for weight loss of $7,74 \%$ of the total mass of the sample, and then the main thermal decomposition was at $200-440{ }^{\circ} \mathrm{C}$ due to chemical degradation by polymer chain scission accounting for weight loss of $75,4 \%$ of the total mass of the sample. Final residue after final heating of $600{ }^{\circ} \mathrm{C}$ of Chlorella-PVA based bioplastic film with ultrasonic pretreatment and Chlorella-PVA based bioplastic film without ultrasonic pre-treatment respectively are 5,03\% and $1,32 \%$. The heat application makes the Chlorella and PVA molecules through hydrogen bonding form more new structure thermal decomposition [7]. The same phenomenon was observed by Asada et al. (2012) where the modification of bioplastic mixture improves the compactness of the crosslinkages within the material proven by the increase of residuals left after heating. The Chlorella-PVA based bioplastic film with ultrasonic pretreatment has more residuals which shows that ultrasonication improves the bioplastic film by creating a more compact crosslinkages between Chlorella and PVA.

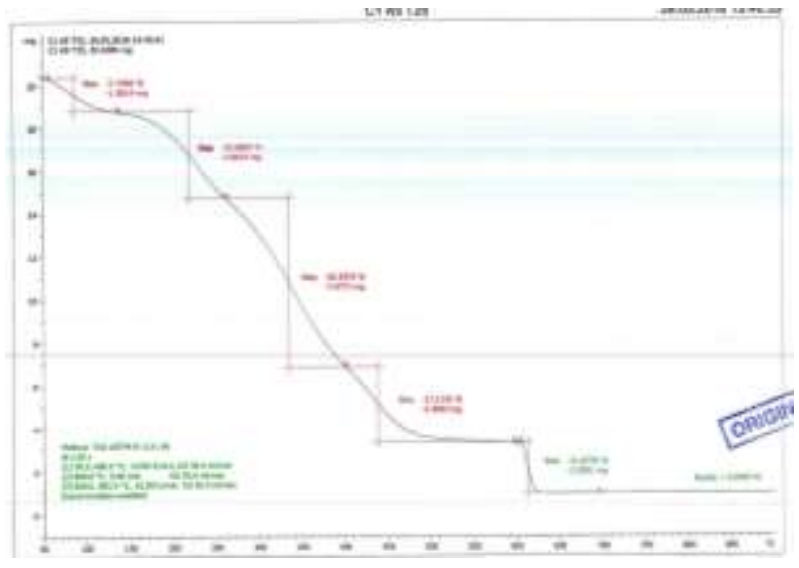

Fig. 1. TGA thermograms of. Chlorella/polyvinyl alcohol blend films with ultrasonic pre-treatment.

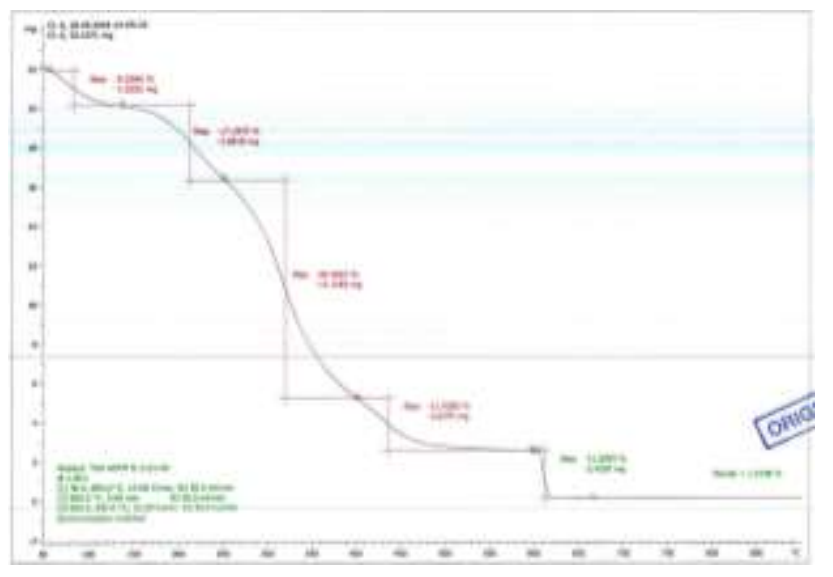

Fig. 2. TGA thermograms of Chlorella/polyvinyl alcohol blend films without ultrasonic pre-treatment. 


\subsection{Surface Morphology and FTIR Analysis}

Micromolecular structure of the bioplastic film was evaluated using SEM and the resulting images are shown in Fig. 3 dan Fig. 4. The images shows that ultrasonic pre-treated Chlorella resulting in more homogenized and less pores bioplastic film, creating a smoother film surface compared with the untreated Chlorella based bioplastic film. Ultrasonication also reduces the particle size of Chlorella. This indicates that ultrasonication can significantly improve the binding of Chlorella and PVA an enhance the dense homogenity of the film.

FTIR analysis of the films resulting FTIR spectra that are shown in Fig. 5 and Fig. 6. The peak in $3650-3200$ $\mathrm{cm}^{-1}$ wavenumber shows that there are free hydroxyl group which causes the films to be soluble in water. The peak in $2200-1800 \mathrm{~cm}^{-1}$ wavenumber shows that there are $\mathrm{C}-\mathrm{H}$ bonds which are hydrogen bonds between amylose and amylopectin in Chlorella [8]. The peak in $1640-1320 \mathrm{~cm}^{-1}$ wavenumber shows that there are amide group and indicates the protein in Chlorella that was not fully bonded with PVA [9]. The peak in $1320-$ $1140 \mathrm{~cm}^{-1}$ wavenumber shows that there are ether group (C-O) and acetal ring $(\mathrm{C}-\mathrm{O}-\mathrm{C})$ which are the bond of PVA and Chlorella [9].

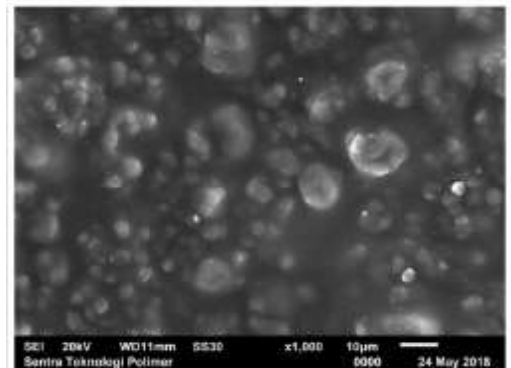

Fig. 3. SEM images of Chlorella/polyvinyl alcohol blend films with ultrasonic pre-treatment.

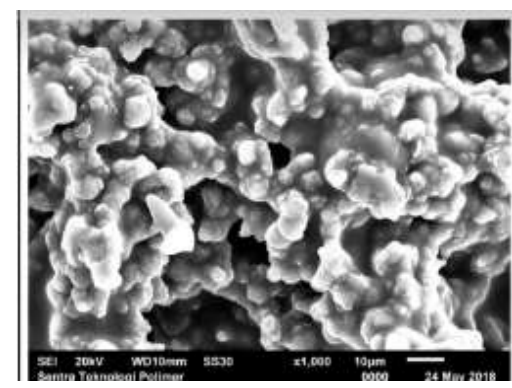

Fig. 4. SEM images of Chlorella/polyvinyl alcohol blend films without ultrasonic pre-treatment.

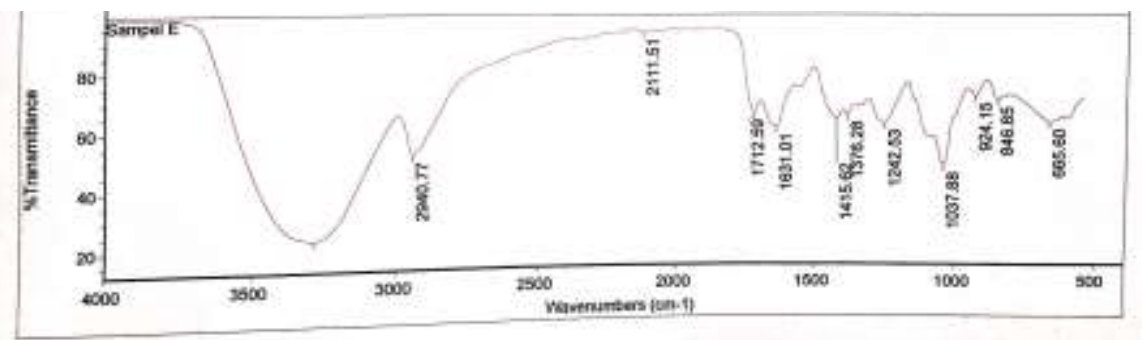

Fig. 5. FTIR spectra of Chlorella/polyvinyl alcohol blend films with ultrasonic pre-treatment.

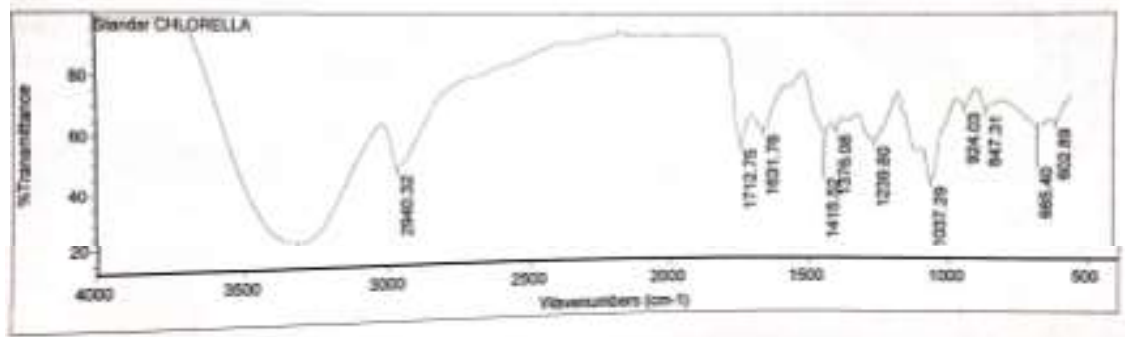

Fig. 6. FTIR spectra of Chlorella/polyvinyl alcohol blend films without ultrasonic pre-treatment.

\section{Conclusions}

In this study, the ultrasonication pre-treatment of Chlorella to produce films with PVA mixture enhances perfomance of the film and could suggest its potential as a eco-sustainable food packaging plastic material. Mechanical test shows the increasing of bioplastic tensile strength up to $15,3 \mathrm{kgf} / \mathrm{cm}^{2}$ and elongation percentage up to $99,63 \%$. Field emission scanning electron microscopy test shows the increasing of bioplastic homogenity and smoother surface with less pores. Fourier transform infrared analysis shows that there are crosslinkages between Chlorella and PVA. Thermal analysis by thermogravimetric analysis shows ultrasonication creates a more compact linkages.

Authors are grateful for the financial support provided by Hibah Publikasi Internasional Terindeks untuk Tugas Akhir Mahasiswa (PITTA) through Universitas Indonesia and research facilities provided by Universitas Indonesia (2478/UN2.R3.1/HKP.05.00/2018). 


\section{References}

1. Wang, K. (2014). Bioplastic Potential of Spirulina Microalgae (Master's thesis) (2014) Retrieved from https://getd.libs.uga.edu/pdfs/wang_kun_201405_m $\underline{\text { s.pdf }}$

2. Wijanarko, A., Dianursanti, Sendjaya, A.Y., Hermansyah, H., Witarto, A.B., Gozan, M., Sofyan, B.T., Asami, K., Ohtaguchi, K., Soemantojo, R.W., Song, S.K. Enhanced Chlorella vulgaris Buitenzorg growth by photon flux density alteration in serial photobioreactors (2008) Biotechnology and Bioprocess Engineering, 13 (4), pp. 476-482.

3. Judawisastra, H., Sitohang, R. D., Marta, L., \& Mardiyati. Water Absorption and Its Effect On The Tensile Properties of Tapioca Starch/Polyvinyl Alcohol (2017) IOP Conf. Series: Materials Science and Engineering, 223.

4. Isnansetyo, A., \& Kurniastuty. Teknik Kultur Fitoplankton Dan zooplankton (1995) Jogjakarta: Kanisius.

5. Asada, C., Doi, K., Sasaki, C., \& Nakamura, Y.. Efficient Extraction of Starch from Microalgae Using Ultrasonic Homogenizer and Its Conversion into Ethanol by Simultaneous Saccharification and Fermentation (2012) Natural Resources, 3, 175179.

6. Wijanarko, A., Dianursanti, Gozan, M., Andika, S.M.K., Widiastuti, P., Hermansyah, H., Witarto, A.B., Asami, K., Soemantojo, R.W., Ohtaguchi, K., Koo, S.S. Enhancement of carbon dioxide fixation by alteration of illumination during Chlorella vulgaris-Buitenzorg's growth (2006) Biotechnology and Bioprocess Engineering, 11 (6), pp. 484-488.

7. Wu, Zhijun, Jingjing Wu, Tingting Peng, Yutong Li, Derong Lin, Baoshan Xing, Chunxiao Li, et al. 2017. Films, Preparation and Application of Starch/Polyvinyl Alcohol/Citric Acid Ternary Blend Antimicrobial Functional Food Packaging. MDPI.

8. Majid, I., Nanda, V., \& Nayik, G. A. Ultrasonication and Food Technology: A Review (2005) Cogent Food and Agriculture, 1.

9. Reis, E. F., Campos, F. S., Lage, A. P., Leite, R. C., Heneine, L. G., Vasconcelos, W. L., Mansur, H. S. Synthesis and Characterization of Poly (Vinyl Alcohol) Hydrogels and Hybrids for rMPB70 Protein Adsorption (2005) Materials Research, 9(2), 185-191. 